\title{
Autoxidation of Salvinorin A under Basic Conditions
}

\author{
Thomas A. Munro ${ }^{\dagger}$, Glenn W. Goetchius ${ }^{\ddagger}$, Bryan L. Roth ${ }^{\ddagger}$, Timothy A. Vortherms ${ }^{\ddagger}$, and Mark \\ A. Rizzacasa ${ }^{*} \dagger$ \\ School of Chemistry, Bio21 Molecular Science and Biotechnology Institute, The University of \\ Melbourne, Victoria, 3010, Australia, and Department of Biochemistry, Case Western Reserve \\ University Medical School, Cleveland, Ohio 44106 \\ †The University of Melbourne. \\ $\ddagger$ Case Western Reserve University.
}

\begin{abstract}
Treatment of salvinorin $\mathrm{A} \mathrm{(1a)} \mathrm{with} \mathrm{KOH}$ in $\mathrm{MeOH}$ gave the enedione 3, for which the dienone structure 7 was recently proposed. Also isolated, after methylation, were the seco-triesters $\mathbf{4 a}-\mathbf{c}$. A mechanism for this unusual series of autoxidations is proposed. Surprisingly, 4a showed weak affinity at the $\kappa$-opioid receptor. Divinatorins $\mathrm{A}-\mathrm{C}(\mathbf{2} \mathbf{a}-\mathbf{c})$ showed no affinity at opioid receptors. Attempted reduction of $\mathbf{3}$ to a novel salvinorin diol (9d) was unsuccessful, but careful deacetylation of salvinorin C (9a) provided a viable route to this compound. A general method for identifying salvinorin 8-epimers by TLC is also presented.
\end{abstract}

\section{Introduction}

Salvinorin A (1a) ${ }^{1}$ is a neoclerodane diterpenoid isolated from the Mexican medicinal plant Salvia divinorum. 1a is an agonist at the $\kappa$-opioid receptor (KOR), ${ }^{2}$ and is the most potent naturally-occurring hallucinogen known. ${ }^{3}$ As a result, both the compound and the plant itself have been prohibited in some countries and several US states. 1a has also attracted growing scientific interest, being the only non-nitrogenous KOR agonist known, with no apparent structural similarity to other ligands. This anomaly has inspired several groups to study the structure-activity relationships of 1 a. $^{4-11}$

*masr@unimelb.edu.au.

Supporting Information Available: Experimental details, characterization data, ${ }^{1} \mathrm{H}$ NMR spectra and IUPAC International Chemical Identifiers (InChIs) of compounds $\mathbf{3}, \mathbf{4 a - c}, \mathbf{8 b}$ and $\mathbf{9 d}$. This material is available free of charge via the Internet at http://pubs.acs.org. 


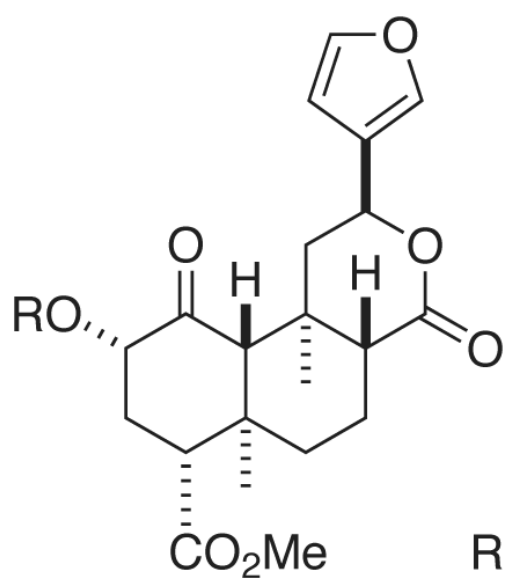

$\begin{array}{ll}\text { 1a } & \mathrm{Ac} \\ \text { 1b } & \mathrm{H} \\ \text { 1c } & \mathrm{Et} \\ \text { 1d } & \mathrm{MOM} \\ \text { 1e } & \mathrm{Bz}\end{array}$

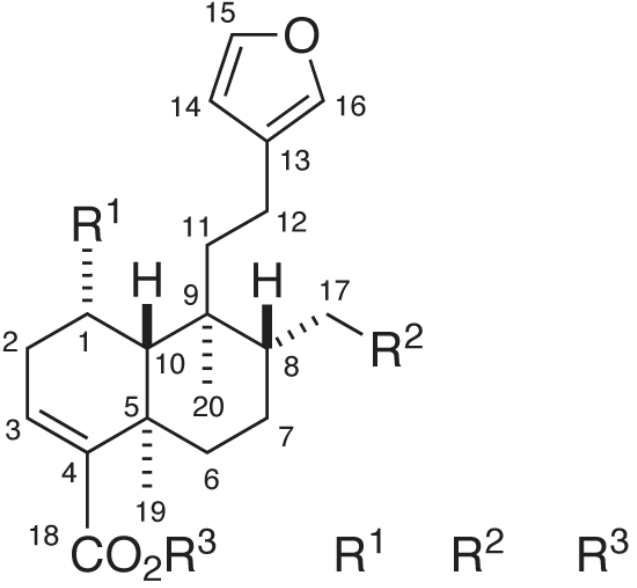

$\begin{array}{llll}\mathbf{2 a} & \mathrm{OH} & \mathrm{H} & \mathrm{H} \\ \mathbf{2 b} & \mathrm{OH} & \mathrm{OH} & \mathrm{Me} \\ \mathbf{2 c} & \mathrm{H} & \mathrm{OAc} & \mathrm{H} \\ \mathbf{2 d} & \mathrm{OH} & \mathrm{OAc} & \mathrm{Me} \\ \mathbf{2 e} & \mathrm{OH} & \mathrm{CHO} & \mathrm{Me}\end{array}$

We recently showed that the ketone and lactone are not involved in activation of the KOR by 1a, while the methyl ester and furan ring are.${ }^{10}$ Consistent with this, recent work has confirmed that steric hindrance around the furan ring ${ }^{12}$ or the $\mathrm{C}-18$ ester $^{9}$ greatly reduce binding affinity. Most work, however, has been devoted to modification of the acetoxy function. More hindered esters show greatly reduced affinity at the KOR. ${ }^{4-6,8}$ The deacetyl compound salvinorin B (1b) ${ }^{13}$ also shows little ${ }^{8}$ or no ${ }^{5}$ affinity. Nonetheless, the acyloxy group is not essential for activity. Some notable examples are the ethyl ether 1c, which displays comparable affinity at the KOR to 1a, and even more remarkably the methoxymethyl ether $\mathbf{1 d}^{8}{ }^{8}$ which exhibits substantially increased (sub-nanomolar) affinity and potency. Another surprise is the benzoate $1 \mathrm{e}^{, 6}$ which is a potent $\mu$-opioid receptor agonist. Some of these compounds also exhibit antagonist activity. ${ }^{10,12}$ Complementing this work, site-directed mutagenesis suggests that 1a and analogues activate the KOR via different residues than conventional ligands. ${ }^{11}$ That such a small body of work should generate so many noteworthy results establishes 1a as a valuable lead for the study of opioid receptors, and for the development of new ligands.

\section{Results and Discussion}

For the purposes of our derivative work, we needed to cleave the methyl ester. While searching for a suitable method, we treated $1 \mathrm{a}$ with $1 \mathrm{M} \mathrm{KOH}$ in $\mathrm{MeOH}$. To our surprise the major product, found in the neutral fraction, was enedione $\mathbf{3}$ (Scheme 1). The ${ }^{1} \mathrm{H}$ spectrum showed two new singlets at $\delta 6.91$ and $6.99 \mathrm{ppm}$. The peak at 6.91 showed no COSY or HMQC crosspeak, and exchanged with $\mathrm{D}_{2} \mathrm{O}$. Such strongly deshielded exchangeable peaks are typical of cyclic $\alpha$ diones, whose enol tautomers are stabilized by internal H-bonds. ${ }^{14}$ Consistent with this, the compound exhibited strong IR absorptions at 3373 and $1651 \mathrm{~cm}^{-1}(\mathrm{OH}$ and enol $\mathrm{C}=\mathrm{C})$. The structure was further elucidated by analysis of the $\mathrm{HMBC}$ spectrum. The quaternary $\mathrm{C}-10$ peak, located unambiguously by its correlations to the H-19 and 20 methyls, showed a correlation 
to the enolic proton, placing the enol at $\mathrm{C}-1$ and the ketone at $\mathrm{C}-2$. The vinylic $\mathrm{H}-3$ peak showed the expected correlations to C-1, 4, 5 and 18 (see Figure 1). UV absorptions at 215, 249 and $324 \mathrm{~nm}$ confirmed an extended $\pi$ system (compare 9a: ${ }^{15} 208 \mathrm{~nm}$ ). HRESIMS confirmed the molecular formula. The remainder of the structure, unchanged from the salvinorins, was fully elucidated and assigned by NMR experiments (DEPT, COSY, HMQC, HMBC, and nOe). The $\mathrm{H}-12$ coupling constants were closer to those of 8-epi-1. $\mathbf{a}^{10}$ than of $\mathbf{1 a}$, suggesting that epimerization at C-8 may have occurred (as is typical for salvinorins and analogues under basic conditions). ${ }^{10}$ However, the $\beta$ configuration of $\mathrm{H}-8$ was evidenced by a diaxial coupling constant $(9.7 \mathrm{~Hz})$. In addition, irradiation of $\mathrm{H}-12$ gave an nOe enhancement of $\mathrm{H}-20$. The structure of $\mathbf{3}$ thus established is remarkably similar to the recently isolated salvinorin $\mathrm{G}(\mathbf{6}){ }^{7}$

The base-soluble fraction was difficult to analyze, smearing on TLC and giving a poorlyresolved ${ }^{1} \mathrm{H}$ NMR spectrum. Surprisingly, at least eight peaks were apparent in the methoxy region. After methylation with $\mathrm{Me}_{3} \mathrm{SiCHN}_{2},{ }^{16} \mathrm{TLC}$ showed only a single spot. ${ }^{1} \mathrm{H}$ NMR analysis, however, revealed three major compounds, which were separated with difficulty by HPLC. Baseline resolution was not achieved, necessitating repeated repurification and poor recoveries. The major product was identified as 1,2-secotriester 4a based on extensive NMR experiments. The $\mathrm{H}-10$ singlet showed an HMBC correlation to the new C-1 ester carbonyl (Figure 1). H-4 showed correlations to C-3, 5 and 10, and formed an isolated spin system with the two deshielded $\mathrm{H}-3$ peaks. This confirmed the location of the new methyl esters at C-1 and 2 , although the three esters were not sufficiently resolved in the 2D spectra to allow individual assignment. The remaining NMR data was very similar to $1 \mathbf{a}$. The chemical shift and coupling constants of $\mathrm{H}-12$ were near-identical to those of 1a, confirming the configuration at C-8. HRESIMS confirmed the molecular formula. The second major product was identified as the 8-epimer $4 \mathbf{b}$ based on the shifts and coupling constants of H-8 and 12 (near-identical to those of 8-epi-1a). ${ }^{10}$ Assignment of the remaining data was straightforward. 2D NMR showed the same correlations as 4a; HRESIMS again confirmed the molecular formula. Interestingly, although $4 \mathbf{a}$ and $\mathbf{4 b}$ cospotted by TLC, they gave different colors with vanillin/ $\mathrm{H}_{2} \mathrm{SO}_{4}$ in EtOH. After development with a heat gun and several minutes' cooling, 4a gave a pink/purple color, while $\mathbf{4 b}$ appeared blue. Similar colors were observed for salvinorins A-E and several derivatives. In all pairs other than $\mathbf{4 a} / \mathbf{4} \mathbf{b}$, the 8-epimer gave a higher $R_{f}$ in $\mathrm{Et}_{2} \mathrm{O}$ or EtOAc/ petrol. Given the tendency for salvinorins to epimerize at C-8 under basic conditions, this information should prove useful for future derivative work.

The third (minor) compound decomposed in $\mathrm{CDCl}_{3}$ before characterization was completed, but was tentatively assigned as $\mathbf{4 c}$. HRESIMS established that the compound was also an isomer of $\mathbf{4 a}$, and the appearance of the same couplings in the COSY spectrum suggested another stereoisomer. The coupling constants of $\mathrm{H}-8$ and 12 established that the C-ring configurations matched those of $4 \mathbf{a}$. Indeed, all of the coupling constants determined were close to those in 4a, whereas many chemical shifts showed large changes. This implied a change in the electronic environment of the coupling protons, without a change in their configuration. The most plausible candidate structure was therefore the 10 -epimer $\mathbf{4 c}$, since $\mathrm{H}-10$ is not coupled. Placing a large substituent in an axial configuration would be expected to affect the conformation of both remaining rings, and hence the chemical shifts around those rings. By contrast, inversion at C-4 would not be expected to dramatically alter the conformations of the rings, but would be expected to alter the coupling constants with the $\mathrm{H}-3$ protons. These couplings were scarcely changed, while the chemical shifts of $\mathrm{H}-4,7,8,10,11$, and 12 (but not $\mathrm{H}-3$ ) were dramatically altered. Thus $\mathbf{4} \mathbf{c}$ is the more plausible structure. The particularly large change at $\mathrm{H}-4$, shifted downfield by $0.83 \mathrm{ppm}$, might be due to falling within the deshielding region of the $\mathrm{C}-1$ carbonyl. Interestingly, Brown found that when 1a was refluxed with $\mathrm{KCN}$ in $\mathrm{CD}_{3} \mathrm{OD}$, deuterium exchange occurred at $\mathrm{H}-2,8$ and 10 but not $\mathrm{H}-4 .{ }^{17}$ In the absence of nOe data, however, the proposed structure $\mathbf{4 c}$ must remain tentative. 
Our results conflict with recently published reports. Tidgewell et al ${ }^{18}$ reported that heating 1a with $\mathrm{NaOH}$ in $\mathrm{MeOH}$ caused cleavage of the methyl ester and opening of the lactone, without giving further detail. Since lactone hydrolysis would be reversed upon neutralization, we interpret this as methanolysis. Presumably ester cleavage was inferred from the formation of a base-soluble fraction, and lactone methanolysis from the methoxy peaks in the ${ }^{1} \mathrm{H}$ NMR spectrum. As shown above, however, the acidic fraction and its methoxy peaks result from cleavage of the $\alpha$-hydroxy ketone. Refluxing the 1-hydroxy derivative $\mathbf{8} \mathbf{a}^{13}$ in $\mathrm{KOH} / \mathrm{MeOH}$ for 30 min resulted only in epimerization at C-8, confirming that neither ester cleavage nor methanolysis occur under these conditions. More recently, Lee et al treated 1a with Ba $(\mathrm{OH})_{2}$ in $\mathrm{MeOH}$. The ${ }^{1} \mathrm{H}$ and ${ }^{13} \mathrm{C}$ NMR data of the product are near-identical to 3 , apart from the omission of the multiplet at $\delta 1.77-1.67 .{ }^{8}$ On the basis of NMR analysis, they propose the dienone structure 7 , which is not consistent with the additional data presented here.

Specifically, HRMS shows no molecular ion corresponding to $\mathrm{C}_{21} \mathrm{H}_{22} \mathrm{O}_{6}(7)$, but a prominent peak corresponding to $\mathrm{C}_{21} \mathrm{H}_{22} \mathrm{O}_{7}(3)$. Further, the singlet at 6.91 cannot be attached to $\mathrm{C}-1$, since it exchanges with $\mathrm{D}_{2} \mathrm{O}$, has no $\mathrm{HMQC}$ crosspeak, and lacks the expected HMBC correlations to C-3, 5, and 9. A corresponding methine peak is also absent from the DEPT spectra. Moreover, deoxygenation would not be expected under these conditions.

By contrast, autoxidation of $\alpha$-hydroxy ketones (acyloins or $\alpha$-ketols) to $\alpha$-diones (diosphenols) under basic conditions is well-established. ${ }^{19-21}$ The reaction consumes one equivalent of $\mathrm{O}_{2}$, generating $\mathrm{H}_{2} \mathrm{O}_{2} \cdot{ }^{21}$ While the autoxidation of unsubstituted ketones requires stronger bases such as $t$-BuOK, $\alpha$-hydroxy ketones are more readily enolized, and the reaction proceeds with $\mathrm{KOH} .{ }^{20}$ A proposed mechanism, via saturated dione 5, is shown in Scheme 2 (the initial deacetylation to $\mathbf{1 b}$ is not shown). Dehydrogenation of $\mathbf{5}$ to form $\mathbf{3}$ is more unusual. While there have been several reports of dehydrogenation of 1,4-diones in alcoholic $\mathrm{KOH},{ }^{22}$ we have not located such a reaction involving a 4-ketoester. However, $\alpha$-diones are much more readily enolized than unsubstituted ketones; in the case of $\mathbf{3}$, no trace of the 1-keto tautomer was detectable by NMR. It is therefore plausible that $\mathbf{5}$ should be extremely reactive, and unsurprising that this compound was not isolated. Consistent with this, Brown's attempts to prepare $\mathbf{5}$ via PCC oxidation of $\mathbf{1 b}$ gave no isolable product. ${ }^{17}$ The alternate pathway, bond cleavage to give the seco-diesters, has numerous precedents. ${ }^{20,23}$ We have based our proposed mechanism on the generally-accepted formation of hydroperoxide intermediates, ${ }^{20}$ although this mechanism has been disputed. ${ }^{23}$ Tautomerization of the enolate or radical will give the regioisomeric diester, which along with epimerization at C-8 and 10 explains the numerous methoxy peaks in the ${ }^{1} \mathrm{H}$ NMR spectrum of the crude product. 


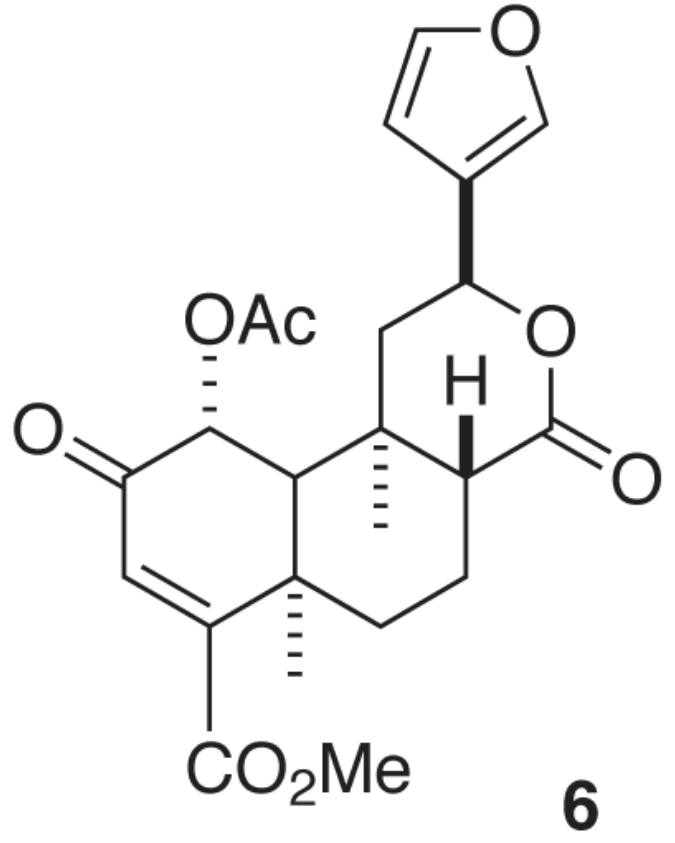

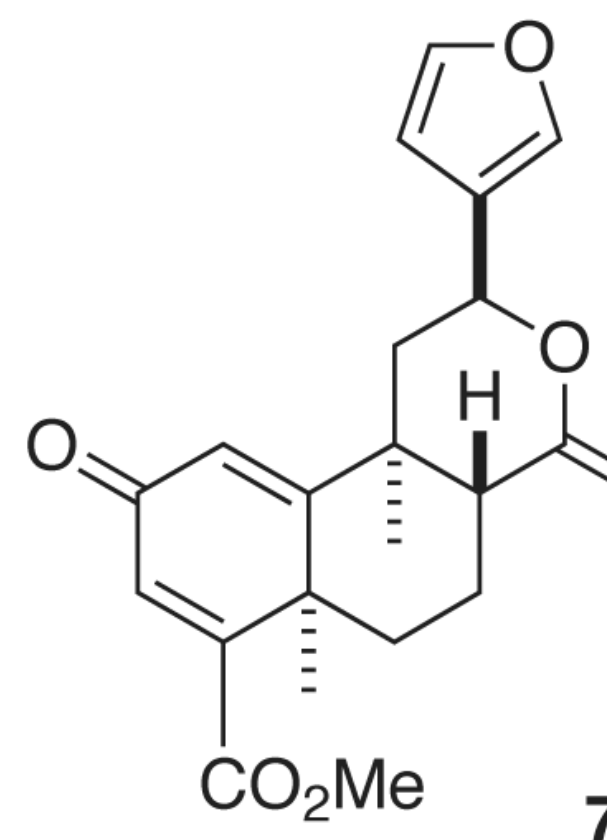

The yield and selectivity of autoxidations of this type can be subject to strong solvent effects. ${ }^{20} \mathrm{We}$ therefore performed the reaction in $\mathrm{EtOH}, i-\mathrm{PrOH}$ and $t-\mathrm{BuOH}$. The resulting neutral and acidic fractions were noticeably more complex. In each case, $\mathbf{3}$ was contaminated by inseparable impurities (presumably including the 8-epimer); the original selection of $\mathrm{MeOH}$ thus proved fortuitous. The reaction proceeded with only traces of oxygen, even when performed under $\mathrm{N}_{2}$ in $\mathrm{MeOH}$ pre-saturated with $\mathrm{N}_{2}$. This is again typical. ${ }^{20,23}$ Nonetheless, we found the reaction faster and more consistent when the solution was saturated with $\mathrm{O}_{2}$. Anther useful refinement was the use of dilute $\mathrm{KOH}$ rather than $\mathrm{NaHCO}_{3}$ to extract the extremely hydrophobic diesters during workup.

The new compounds $\mathbf{3}$ and $\mathbf{4 a}$ were screened for binding affinity at cloned opioid receptors in vitro, as previously described. ${ }^{10} 3$ was inactive at the KOR $\left(K_{i}>10 \mu \mathrm{M}\right)$, as Lee et al reported for 7. ${ }^{8}$ Surprisingly, 4 a showed weak affinity at the KOR $\left(K_{i}=2.9 \pm 0.4 \mu \mathrm{M}\right)$. Both compounds were inactive at $\delta$ and $\mu$ subtypes. The result for 4 a provides further evidence that the 2-acyloxy function in 1a is not essential for binding, but that modifying this function usually reduces affinity. In light of these findings, we also screened divinatorins A-C $(\mathbf{2 a}-\mathbf{c}),{ }^{24}$ which we had previously isolated from S. divinorum. These compounds showed no affinity at $\kappa, \delta$ or $\mu$ subtypes $\left(K_{i}>10 \mu \mathrm{M}\right)$. Lee et al also found $2 \mathrm{c}$ inactive at the KOR. ${ }^{7}$ Intriguingly, however, the recently isolated divinatorin $\mathrm{D}(\mathbf{2 d})^{7}$ showed weak affinity $\left(K_{i}=230 \mathrm{nM}\right.$ vs $1.0 \mathrm{nM}$ for 1a). Thus, either of the $\mathrm{A}$ or $\mathrm{C}$ rings can be cleaved without total loss of affinity. Apart from this greater conformational freedom, $\mathbf{2 d}$ not only lacks the 2-acetoxy function, but also possesses a $1 \alpha$-hydroxy group, which drastically reduces activity in analogues of $1 \mathbf{1 a}^{10}$ The structure-activity relationships of this compound are thus markedly different from those of 1a. Given that its deacetyl analogues $\mathbf{2 b}$ and $\mathbf{2} \mathbf{e}^{7}$ are inactive, perhaps the 17 -acetoxy function substitutes for the furan ring in binding. However $\mathbf{2 c}$, which also possesses this function, is inactive. Further exploration of this productive region of chemical space is clearly warranted. 
Given the unexpected installation of the 3,4 double bond in $\mathbf{3}$, we thought the compound might provide a route to diol $9 \mathrm{~d}$. This would then give access to salvinorins $\mathrm{C}(\mathbf{9 a}),{ }^{15} \mathrm{D}(\mathbf{9 b})$ and $\mathrm{E}$ (9c), ${ }^{25}$ which occur in S. divinorum in much lower levels than $\mathbf{1 a}$. However, $\mathrm{NaBH}_{4}$ in EtOH/ $\mathrm{CH}_{2} \mathrm{Cl}_{2}$ resulted in conjugate addition and epimerization, giving the known 8-epi-diol $\mathbf{8} \mathbf{b}^{15}$ in low yield (Scheme 3). Attempted reduction with $\mathrm{NaBH}_{4}-\mathrm{CeCl}_{3}$ in $\mathrm{MeOH}^{26}$ (with or without sonication $)^{27}$ was also unsuccessful, giving a complex mixture whose unstable major components retained the characteristic enedione peaks at $\delta 6.8$ and $7.0 \mathrm{ppm}$ (these products cospotted with the starting material, making the reaction difficult to follow, but gave a darker purple with vanillin). Enolized $\alpha$-diones form complexes with a variety of metal salts such as $\mathrm{FeCl}_{3} ; 28$ it appears likely that such an enolic complex forms in preference to the desired ketone - solvent $-\mathrm{Ce}^{3+}$ complex, ${ }^{26}$ and the reaction therefore does not follow the desired course. The only successful precedent we located for this reduction involved non-enolizable enediones.

${ }^{29}$ It might be possible to prevent this problem by protection of the enol, but attempted TES protection was unsuccessful.

As an alternative route, the target diol 9d was prepared by deacetylation of 9a. Tidgewell et al's now-standard conditions for $\mathbf{1 a}\left(\mathrm{Na}_{2} \mathrm{CO}_{3} \text { in minimal } \mathrm{MeOH}\right)^{18}$ gave almost exclusively the 8-epimer, but we found this could be prevented by addition of $\mathrm{CH}_{2} \mathrm{Cl}_{2}$, affording $\mathbf{9 d}$ from $9 \mathbf{a}$ or $9 \mathbf{b}$ in up to $86 \%$ yield. Reacetylation under standard conditions progressed slowly through intermediate $9 \mathbf{b}$ and $9 \mathbf{c}$ to give $9 \mathbf{a}$. While no-one has yet isolated $9 \mathbf{d}$ from $S$. divinorum, it may be that the compound occurs in the plant in very low levels. This would be expected if its formation were the rate-limiting step on the path to $9 \mathbf{a}-\mathbf{c}$. Alternatively, current isolation procedures may give poor recoveries. Indeed, we found that like $\mathbf{1 b}$, the compound precipitates when loaded on silica gel in most solvent systems. Stripping the column with $\mathrm{MeOH} /$ $\mathrm{CH}_{2} \mathrm{Cl}_{2}$ was required to achieve satisfactory recovery.

\section{Conclusions}

In summary, we have identified the actual products of the treatment of 1a with hydroxide in $\mathrm{MeOH}$, resolving recent conflicting reports. One of these products, $\mathbf{4 a}$, shows mild affinity at the KOR, further elucidating the structure-activity relationships of 1a. Finally, interconversion of salvinorins $\mathrm{C}-\mathrm{E}(\mathbf{9 a}-\mathbf{c})$ with the novel diol $9 \mathrm{~d}$ provides further confirmation of the structure of these compounds.

\section{Supplementary Material}

Refer to Web version on PubMed Central for supplementary material.

\section{Acknowledgments}

This work was supported by Grants KO2MH01366 and RO1DA-017204 and the National Institute of Mental Health Psychoactive Drug Screening Program (B.L.R.), the Australian Research Council (M.A.R.), and the Commonwealth Department of Education, Science and Training (T.A.M.).

\section{References}

[1]. Ortega A, Blount JF, Manchand PS. J. Chem. Soc., Perkin Trans. 1 1982:2505-2508.

[2]. Roth BL, Baner K, Westkaemper R, Siebert D, Rice KC, Steinberg S, Ernsberger P, Rothman RB. Proc. Natl. Acad. Sci. U. S. A 2002;99:11934-11939. [PubMed: 12192085]

[3]. Siebert DJ. J. Ethnopharmacol 1994;43:53-56. [PubMed: 7526076]

[4]. Béguin C, Richards MR, Wang Y, Chen Y, Liu-Chen L-Y, Ma Z, Lee DY, Carlezon WA, Cohen BM. Bioorg. Med. Chem. Lett 2005;15:2761-2765. [PubMed: 15869877]

[5]. Chavkin C, Sud S, Jin W, Stewart J, Zjawiony JK, Siebert DJ, Toth BA, Hufeisen SJ, Roth BL. J. Pharmacol. Exp. Ther 2004;308:1197-1203. [PubMed: 14718611] 
[6]. Harding WW, Tidgewell K, Byrd N, Cobb H, Dersch CM, Butelman ER, Rothman RB, Prisinzano TE. J. Med. Chem 2005;48:4765-4771. [PubMed: 16033256]

[7]. Lee DY, Ma Z, Liu-Chen L-Y, Wang Y, Chen Y, Carlezon WA, Cohen B. Bioorg. Med. Chem 2005;13:5635-5639. [PubMed: 16084728]

[8]. Lee DY, Karnati VV, He M, Liu-Chen L-Y, Kondareti L, Ma Z, Wang Y, Chen Y, Béguin C, Carlezon WA, Cohen B. Bioorg. Med. Chem. Lett 2005;15:3744-3747. [PubMed: 15993589]

[9]. Lee DY, He M, Kondaveti L, Liu-Chen LY, Ma Z, Wang Y, Chen Y, Li JG, Béguin C, Carlezon WA, Cohen B. Bioorg. Med. Chem. Lett 2005;15:4169-4173. [PubMed: 16051487]

[10]. Munro TA, Rizzacasa MA, Roth BL, Toth BA, Yan F. J. Med. Chem 2005;48:345-348. [PubMed: 15658846]

[11]. Yan F, Mosier PD, Westkaemper RB, Stewart J, Zjawiony JK, Vortherms TA, Sheffler DJ, Roth BL. Biochemistry 2005;44:8643-8651. [PubMed: 15952771]

[12]. Harding WW, Tidgewell K, Schmidt M, Shah K, Dersch CM, Snyder J, Parrish D, Deschamps JR, Rothman RB, Prisinzano TE. Org. Lett 2005;7:3017-3020. [PubMed: 15987194]

[13]. Valdés LJJ, Butler WM, Hatfield GM, Paul AG, Koreeda M. J. Org. Chem 1984;49:4716-4720.

[14]. Silverstein, RM.; Webster, FX.; Kiemle, D. Spectrometric Identification of Organic Compounds. Vol. 7th ed. Wiley; New York: 2005. p. 153

[15]. Valdés LJJ, Chang HM, Visger DC, Koreeda M. Org. Lett 2001;3:3935-3937. [PubMed: 11720573]

[16]. Presser A, Huefner A. Monatsh. Chem 2004;135:1015-1022.

[17]. Brown, L. Ph.D. thesis. University of Michigan; Ann Arbor, MI: 1984. The Stereocontrolled Synthesis of Optically Active Vitamin E Side Chains. II. Benzoyl Triflate and its Application in the Determination of the Absolute Configuration of Divinorin A and B, and Terrecyclic acid; $p$. 82-91.

[18]. Tidgewell K, Harding WW, Schmidt M, Holden KG, Murry DJ, Prisinzano TE. Bioorg. Med. Chem. Lett 2004;14:5099-5102. [PubMed: 15380207]

[19]. Caton MPL, Darnbrough G, Parker T. Tetrahedron Lett 1980;21:1685-1686.

[20]. Lack RE, Ridley AB. J. Chem. Soc., C 1968;3017:3020.

[21]. WeissbergerASchwarzeWLiebigs Ann. Chem19314875361 and references therein.

[22]. DaubenWGBoswellGATempletonWJ. Org. Chem19602518531855 and references therein.

[23]. Slavikova B, Kasal A, Budesinsky M. Collect. Czech. Chem. Commun 1999;64:1125-1134.

[24]. Bigham AK, Munro TA, Rizzacasa MA, Robins-Browne RM. J. Nat. Prod 2003;66:1242-1244. [PubMed: 14510607]

[25]. Munro TA, Rizzacasa MA. J. Nat. Prod 2003;66:703-705. [PubMed: 12762813]

[26]. Gemal AL, Luche JL. J. Am. Chem. Soc 1981;103:5454-5459.

[27]. Marchand AP, Reddy GM. Org. Prep. Proced. Int 1990;22:528-531.

[28]. Zsakó J, László T. Rev. Roum. Chim 1981;26:237-243.

[29]. Rubin Y, Knobler C, Diederich F. J. Am. Chem. Soc 1990;112:1607-1617. 


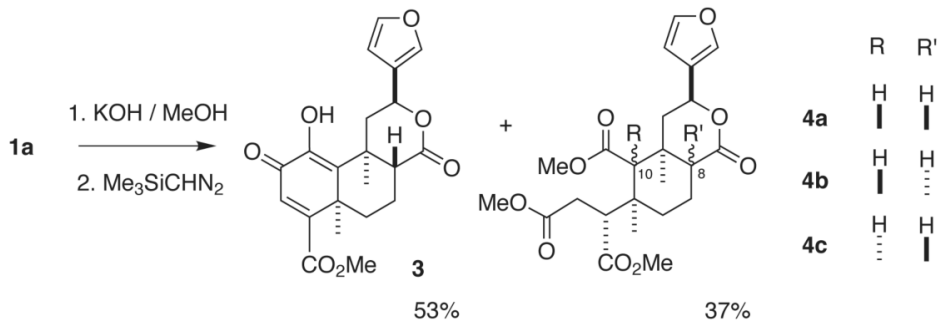

Scheme 1. 

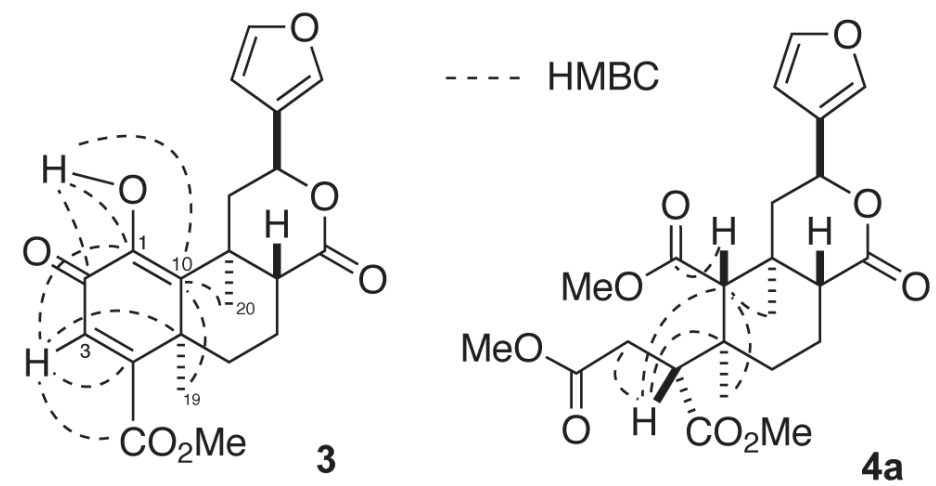

Figure 1.

Key HMBC correlations of $\mathbf{3}$ and $\mathbf{4 a}$. 


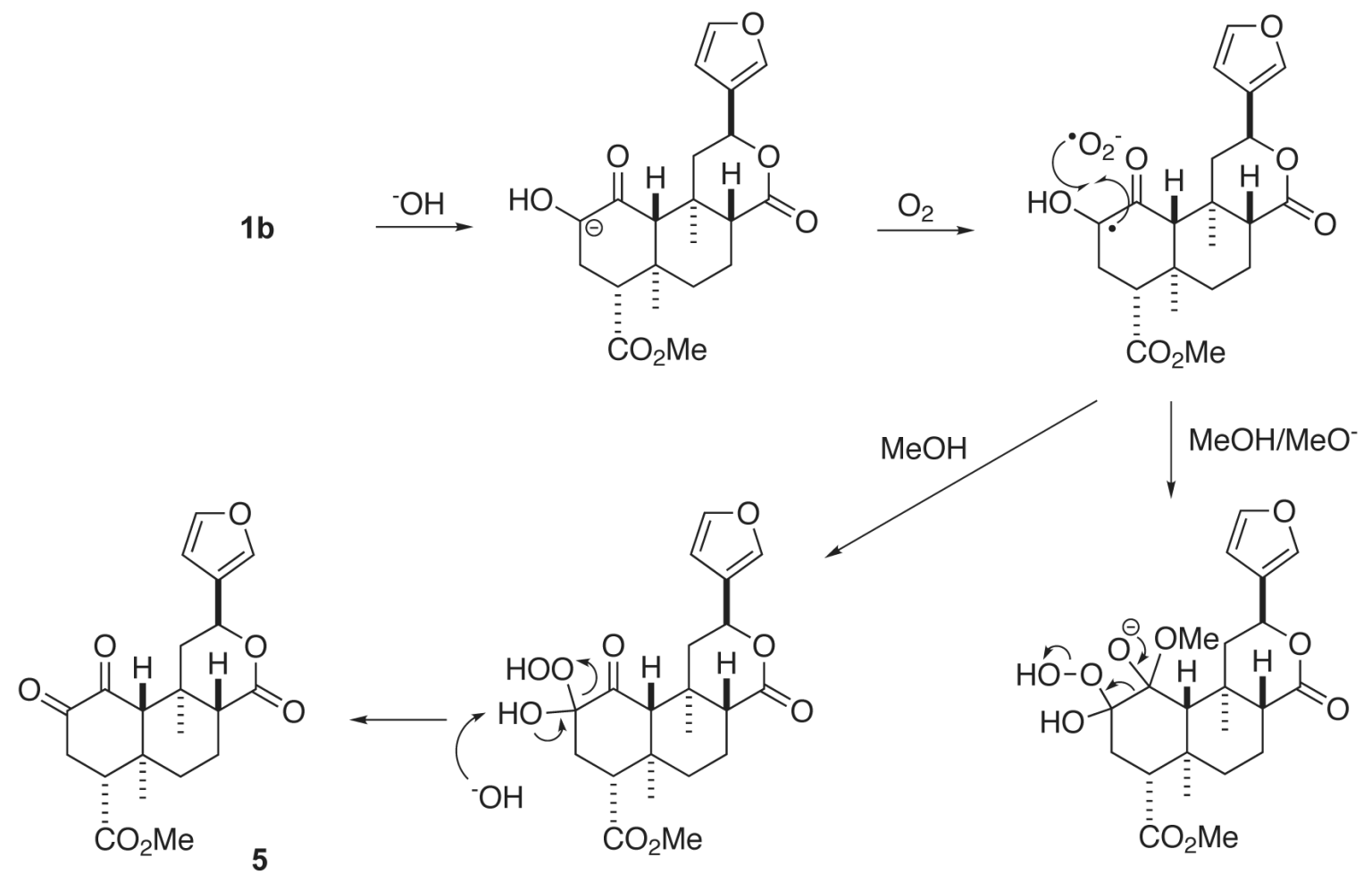

1) $\mathrm{OH} \downarrow$ 2) $\mathrm{O}_{2}$

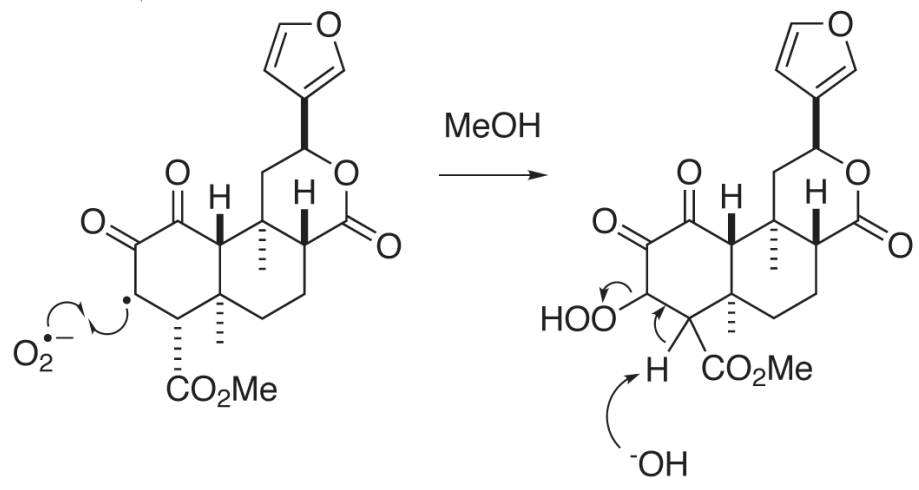

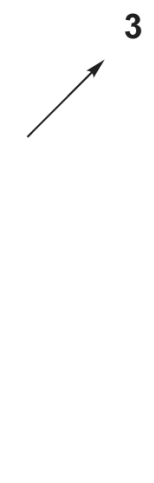<smiles>COC[C@@H](CC(=O)O)[C@]12CC[C@@]3(C(=O)OC(c4ccoc4)C[C@H]3[C@@H]1C(=O)OC)C2=O</smiles>

Scheme 2.

Proposed mechanism of the autoxidation. 


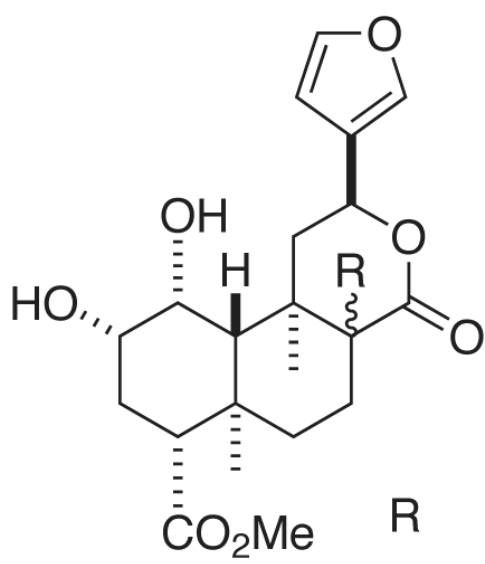

$8 \mathrm{a} \stackrel{\mathrm{H}}{\mathrm{I}}$

8b $\stackrel{\mathrm{H}}{\mathrm{H}} \longleftarrow \mathrm{NaBH}_{4}$

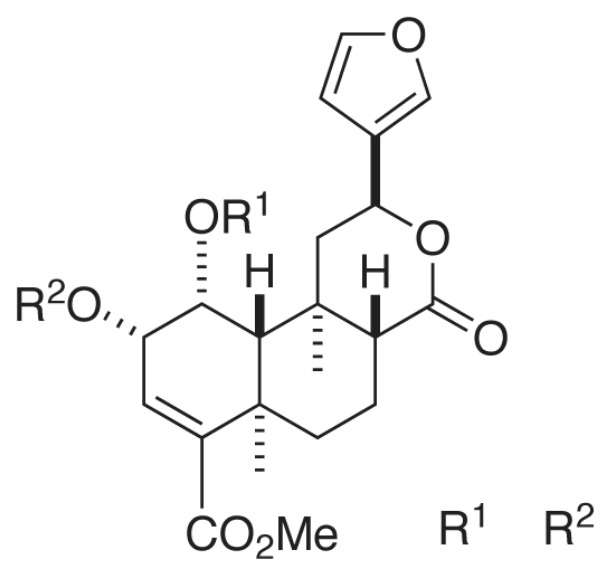

9a $\mathrm{Ac} \mathrm{Ac}-\mathrm{Na}_{2} \mathrm{CO}_{3}$,

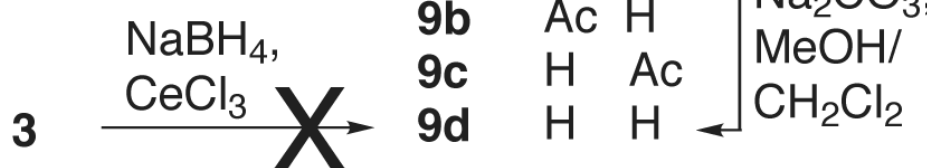

Scheme 3.

Attempted reductions of 3 . 